\title{
LEONARDO POLO Y LA INTENCIONALIDAD: LA REVISIÓN Y REACTUALIZACIÓN DE UN CONCEPTO CLÁSICO
}

\author{
LEONARDO POLO AND INTENTIONALITY: REVISION AND \\ REACTUALIZATION OF A CLASSIC NOTION
}

\author{
$\mathrm{M}^{\mathrm{a}}$ Idoya Zorroza \\ Universidad de Navarra (España)
}

Recibido: 10-10-2014

Aceptado: 02-11-2014

Resumen: La recuperación de la noción de intencionalidad (un término escolástico) con el pensamiento de Brentano y la fenomenología de Husserl tenía como intención garantizar la objetividad del conocimiento humano frente a diversas formas de psicologismo y reductivismo. Sin embargo, se realiza una modificación conceptual que para algunos autores da razón de dos hechos: el primero, mantener un idealismo de nuevo cuño; el segundo, la necesidad de otra vía para garantizar el realismo gnoseológico. En Leonardo Polo (1926-2013), este doble objetivo se realiza profundizando en la noción clásica de intencionalidad, recuperando el sentido de la energeia aristotélica y su articulación entre inmanencia y trascendencia.

Palabras-clave: intencionalidad, Brentano, Husserl, Leonardo Polo, acto, objeto, energeia, inmanencia.

\begin{abstract}
The recovery of the notion of intentionality (a Scholastic term) in Brentano's thought and Husserl's phenomenology had the intent of guaranteeing the objectivity of human knowledge against diverse forms of psychologism and reductivism. However, a conceptual modification developed from it that, for some authors, accounts for two facts: first, it made the establishing of a new sort of idealism possible; secondly, it made evident that a new way for guaranteeing gnoseological realism was necessary. Leonardo Polo (1926-2013) accomplishes this goal by going into detail about the classical notion of intentionality, recovering the classic sense of the Aristotelian energeia, and its articulation of immanence and transcendence

Key-words: intentionality, Brentano, Husserl, Leonardo Polo, act, object, energeia, immanence.
\end{abstract}


Cuando en Leipzig, en $1874^{1}$, un joven profesor propone la recuperación de la noción clásica de intencionalidad con objeto de recuperar para la filosofía, la psicología y el conocer humano un estatuto diferenciado, estaba lejos de advertir que su primera propuesta significaría la apertura de un espacio para el filosofar ${ }^{2}$ que pondría las bases de una dirección superadora del pensamiento propiamente moderno. Para Brentano, la cualidad que distingue y caracteriza lo -llamémosle así- mental o espiritual por contraposición a lo físico será justamente la intencionalidad. Sobre esa primera descripción de Brentano «todo fenómeno psíquico se caracteriza por aquello que los escolásticos del medievo denominaron la presencia intencional», Edmund Husserl desarrollará un análisis de la intelección depurada del psicologismo y subjetivismo de muchas teorías para establecer el carácter objetual de la intelección ${ }^{3}$. De manera que la garantía de un dominio propio y específico para definir la particular actividad que ejerce el conocer, en particular, pasaba por la recuperación de una de las más importantes nociones medievales, la de la intencionalidad cognoscitiva ${ }^{4}$.

Para la fenomenología, intencionalidad señala el esencial carácter remitente del acto psíquico: una «relación a un contenido», «dirección a un objeto», con expresiones de Brentano. O, en Husserl, la definición propia del acto o vivencia intencional, en concreto, el carácter esencial común a toda vivencia por la que se refiere a algo objetivo, sea cual sea la forma de ese referirse; es «la

[1] Se trata de la primera edición de la obra de Brentano, F.: Psychologie vom empirischen Standpunkt. Leipzig, 1874; Hamburg: Felix Meiner Verlag, ${ }^{3} 1973$; traducción castellana parcial: Psicología. Traducción de José Gaos, Madrid: Revista de Occidente, 1926 (son textos extraidos de dos obras: Psychologie vom empirischen Standspunkt, v. II, c. 1 y Von der Klassifikation der psychischen Phänomene). Sobre Brentano, cfr. Cruz Hernández, M.: Francisco Brentano. Salamanca: Acta Salmanticensia, Filosofía y Letras, VI, 2, Universidad de Salamanca, 1953; La doctrina de la intencionalidad en la fenomenología. Salamanca: Acta Salmanticensia, Universidad de Salamanca, 1958; Satué, A.: La doctrina de la intencionalidad en Franz Brentano. Barcelona: Consejo superior de Investigaciones Científicas, Instituto Luis Vives de Filosofía, 1961; Chirinos, M. P.: Intencionalidad y verdad en el juicio. Una propuesta de Brentano. Pamplona: Eunsa, 1994; Moran, D.: Introduction to Phenomenology. New York: Routledge, 2000.

[2] Zubiri, X.: Naturaleza, historia, Dios. Madrid: Alianza, ${ }^{9} 1987$, p. 13, especialmente destacando la labor continuadora de esta idea de Franz Brentano en la fenomenología de Edmund Husserl.

[3] Cfr. Husserl, E.: Investigaciones lógicas (Logische Untersuchungen, Max Niemeyer Verlag, 1913). 2 vols, trad. Manuel G. Morente / José Gaos, Madrid: Alianza, 1999, vol. I, p. 219 y ss.

[4] El término intentio o intencionalidad puede tomar diversas significaciones en la filosofía medieval, aunque la más relevante ahora es la gnoseológica que está cifrada en la posesión intelectual (espiritual) de la forma de la cosa (cfr. Hayen S.I, A.: L'intetionnel selon Saint Thomas. Bruxelles: Desclée de Brouwer, ${ }^{2} 1954$; Moya, P.: La intencionalidad como elemento clave en la gnoseología del Aquinate. Pamplona: Cuadernos de Anuario Filosófico, Serie Universitaria, Servicio de Publicaciones de la Universidad de Navarra, 2000). En relación a la intención como propiedad del acto de dirigirse a, referirse o remitirse a un objeto (Brentano y la fenomenología) hay sin embargo una modificación conceptual (cfr. Chirinos M. P.: Intencionalidad y verdad cit., pp. 45-66; sobre la intencionalidad en Brentano).

THÉMATA. Revista de Filosofía, №50 julio-diciembre (2014) pp.: 303-312 doi: 10.12795/themata.2014.i50.15 
naturaleza propia de los actos bajo la imagen del apuntar hacia $»^{5}$. Esa propiedad distintiva es para Brentano el carácter esencial o naturaleza propia de los actos de conciencia. De este modo, el acto de conocimiento, que la psicología ha visto como un determinado acto psíquico o vital, se revela para la fenomenología en lo que es esencialmente como acto: un acto esencialmente distinto del físico y definido por su constitutiva referencia a algo otro. Este acto, en resumen, queda confirmado como acto intencional. Esa peculiar referencia del acto es la marca distintiva de la noción fenomenológica de intencionalidad.

La filosofía contemporánea recurre, por tanto, con Brentano y Husserl a la noción de intencionalidad para resolver aquel problema heredado de la filosofía moderna que, esquemáticamente, podía ser planteado en estos términos: si el conocer es algo activo, lo conocido es, en realidad, algo producido por él, algo que es de alguna manera suyo. Por ello, pretender que al conocer tenemos lo real es a lo más una ingenuidad filosófica o un sentimiento injustificado, en todo caso una posición falta de crítica. Si es mero recibir, no es conocimiento; es, a lo más, un hecho físico precognoscitivo; porque si es cognoscitivo, conocemos en la medida en que damos a lo conocido objetividad (diría Kant: conocemos lo que la subjetividad misma pone). Si lo conocido es otro que la conciencia no es conocido; si es conocido, entonces no es, en último término, realmente otro, sino efecto, resultado o posición de esa misma conciencia. La defensa del carácter activo del conocer en la filosofía moderna, había llevado en último término a perder la inmediatez gnoseológica de lo real: lo real no es esencialmente algo que preceda, guíe o determine el conocer (un principio rector), sino lo sometido a la función espontánea, directiva y autónoma del sujeto cognoscente ${ }^{6}$.

Si la intelección es intencional, como plantea la fenomenología, si nuestro conocer es de lo otro distinto de la conciencia, ha de sernos de alguna forma dado eso otro. La intelección recibe de algún modo lo conocido; sin embargo, ese recibir no puede ser entendido como un necesario momento de inmutación física. Primero, porque afirmar un momento precognoscitivo, causal de inmutación física no impide la posición de un inmanentismo gnoseológico ${ }^{7}$ : señalar la necesidad

[5] Brentano, F.: Psicología cit., pp. 27-29. «Todo fenómeno psíquico está caracterizado por lo que los escolásticos de la Edad Media han llamado la inexistencia intencional (o mental) de un objeto, y que nosotros llamaríamos, si bien con expresiones no enteramente inequívocas, la referencia a un contenido, la dirección hacia un objeto (por el cual no hay que entender aquí una realidad), o la objetividad inmanente. [...] Con lo cual podemos definir los fenómenos psíquicos diciendo que son aquellos fenómenos que contienen en sí, intencionalmente, un objeto». Ver también Husserl, E.: Investigaciones lógicas cit., II, pp. 498 y ss. De hecho, el mundo de la objetividad logrado por Husserl puede sugerir un tercer reino sustentado trascendentalmente (idealmente) por una subjetividad: una nueva forma de idealismo trascendental.

[6] Prólogo de Antonio Millán-Puelles en Gómez Romero, I.: Husserl y la crisis de la razón. Madrid: Cincel, 1986; Ortega y Gasset, J.: "Las dos grandes metáforas" en Obras completas, II, Madrid: Revista de Occidente, 1966, pp. 387-400.

[7] Por ejemplo, en la Crítica de la razón pura de I. Kant (edición de P. Ribas, Madrid: Alfaguara,

THÉMATA. Revista de Filosofía, №50 julio-diciembre (2014) pp.: 303-312

doi: 10.12795/themata.2014.i50.15 
de una pasividad o afección física no es obstáculo para considerar que lo conocido es esencialmente resultado de una posición intelectiva inmanente. Además (y aquí se insertaría el esfuerzo fenomenológico en torno al tema) el descubrimiento de la alteridad en la conciencia no argumenta a favor del el carácter eficiente de la realidad allende y la pasividad de la conciencia (el argumento del -así llamado-realismo ingenuo) sino, en otro orden de argumentación, sólo afirma que en la intelección estamos hablando de un acto que constitutivamente es, en cuanto acto, determinado por algo otro (objeto o realidad) ${ }^{8}$.

Es posible comprender qué sea propiamente la intelección en cuanto hablamos de un acto no activo (al modo físico), un acto intencional; es la propuesta de Brentano que asume Husserl: un acto de este tipo es acto, acto receptivo o abierto a lo otro que no es él (el noema, elemento respectivo que lo constituye como acto y acto intencional). Con la fenomenología, por tanto, se pretende hablar de la intelección con categorías conceptuales que no se ajustan al esquema causa-efecto, acción-pasión, etc. La intelección será un peculiar acto en el cual hay una actividad no productiva y una receptividad objetiva que no se identifica con la pasividad: el tener intelectivo de aquello que afecta no se resuelve en un estar afectado; pues, en todo caso, se tiene (lo que afecta) en lo que es en sí y no en el efecto producido en mí.

1978), encontramos que, al tiempo que se afirma la posición y construcción subjetiva del objeto de conocimiento, se requiere la suposición de una realidad exterior «fuera de mí y con lo cual me tengo que considerar en relación», (BXXXVIII-BXLI). La afirmación de una realidad exterior que impulse la actividad cognoscitiva no es garantía de realismo gnoseológico, empero.

[8] Así, a la filosofía moderna, que habría despertado al descubrimiento del carácter activo, libre y configurador de la subjetividad humana, se le critica el que lo hubiera interpretado según parámetros eficientes, la actividad subjetiva encontraba en sí la norma, ley y objetividad de lo conocido o configurado. Por ello la primera diferencia necesaria es la que hay entre actividad y acto. Sólo un acto no entendido de modo eficiente puede ser activo pero receptivo: puede en cuanto acto encontrar en lo otro que actualiza, su norma y objetividad. Sobre la incomprensión del carácter específicamente activo del acto de conocer, según Polo (conculcación del axioma A), cfr. Polo, L.: Curso de teoría del conocimiento, 4 vols., Pamplona: Eunsa, 1984-1996; especialmente en vol. I, pp. 69-72.

[9] La filosofía de Aristóteles y el realismo clásico ha puesto distancia entre el recibir intelectivo y cualquier tipo de recibir físico, para justificar la especificidad del conocer y su inmaterialidad. Por ello, hablar de inmutatio como origen del conocimiento exigiría diferenciar una inmutatio de carácter físico de otra propiamente espiritual o inmaterial. Esta diferenciación es esencial: no significa que el tener el objeto, lo real, es tener ni actual ni virtualmente lo conocido con su modo de ser "físico», y en su presentarse físico; lo real tiene que estar y tiene que ser dado de otro modo, tanto si hablamos del conocimiento sensible como del conocimiento intelectual. Es en ese «de otro modo» en el que el realismo gnoseológico juega su baza más importante. Por un lado no puede excluir una explicación de tipo causal y física, pues real y efectivamente lo real nos afecta de modo físico. Por otro, no puede entenderse como un desencadenante de la acción espontánea del entendimiento. La filosofía medieval situaba conceptualmente en este particular quicio el tema de la species: la forma de lo conocido (la misma forma de lo conocido) pero inmaterializada (tenida de un modo no físico). Véase, Floucat, Y.: "L'intellection et son verbe selon S. Thomas d'Aquin" en Revue Thomiste 97-3, 1997, pp. 443-484 y pp. 640-693; aquí pp. 446 ss., además del trabajo citado de A. Hayen.

THÉMATA. Revista de Filosofía, №50 julio-diciembre (2014) pp.: 303-312 doi: 10.12795/themata.2014.i50.15 
En último término lo que se está diciendo es que hay dos momentos de diferente signo, esencial y formalmente diferenciados incluidos en el hecho intelectivo: uno de tipo fáctico o psicológico y otro de tipo intencional. Su confusión (fruto de no haber advertido suficientemente su diferenciación) ha distorsionado los elementos básicos de la gnoseología moderna ${ }^{10}$. En cuanto acto, la intelección es determinada (por la forma inteligible) sin dejar de ser activa: la intelección es en cuanto recibe y es determinada por algo, a modo de una potencia, pero el modelo hilemórfico ha sido traspuesto a un plano diferente, con unas connotaciones propias. Allí, tomado de modo más literal, intencionalidad podría traducirse (apelando a su vocablo original latino) como tender a (tendere-in), tender a otro. Este sería el sentido atribuido por Husserl a lo intencional.

Sin embargo, el desarrollo de la fenomenología advirtió que proponer un objeto como correlato de un tender volvía a perder lo real para el conocer refugiándose en un idealismo de nuevo cuño. En esta denuncia nos encontramos con dos respuestas diferenciadas protagonizadas por dos de los autores más originales y sugerentes del pensamiento español contemporáneo: Xavier Zubiri (1898-1983) y Leonardo Polo (1926-2013). El descubrimiento brentaniano (o mejor dicho, la recuperación fenomenológica del concepto) de la intencionalidad fue bien acogido en cuanto se presentó como la superación del inmanentismo moderno -la afirmación de que la conciencia no lo era de contenidos sino que era referencial, su ser era no un tener sino un intender a lo que ella no era-; sin embargo al poco levantó severas críticas por cuanto lo que se entrevió como una salida al idealismo moderno no respondía a todas las expectativas de lograr una filosofía realista (una gnoseología realista) y en la práctica se convertía en una forma más sutil de configuración del objeto (de ahí la crítica de psicologismo de Husserl a Brentano y de idealismo de los discípulos de Husserl a su maestro).

Sin entrar aquí a una comparación entre ellos -como empecé en otro lugar ${ }^{11}$ - sí podemos resumir a grandes rasgos que, para Zubiri, advertir la insuficiencia de la intencionalidad fenomenológica le lleva a criticarla y rechazar que el conocimiento sea formalmente intencionalidad: el conocer no es un tender a sino un estar en: el estar algo meramente actualizado en la inteligencia quedando no ya como objeto sino como formalidad de realidad ${ }^{12}$. En cambio,

[10] Tesis similares son las defendidas por Millán-Puelles, A.: La estructura de la subjetividad. Madrid: Rialp, 1963; Teoría del objeto puro. Madrid: Rialp, 1996; y Llano, A.: Gnoseología. Pamplona: Eunsa, 1987; El enigma de la representación. Madrid: Síntesis, 1999; Metafísica y lenguaje, Pamplona: Eunsa, 1983, al considerar los elementos claves de una teoría de la intelección realista.

[11] En el artículo "Dos caminos del objeto a la realidad: Xavier Zubiri y Leonardo Polo" en Studia Poliana 7, 2005, pp. 143-172.

[12] Zubiri rechaza la noción de «objeto» (uno de los términos que en filosofía que resultan ambiguos dada la cantidad y diversidad de contenidos semánticos que contienen (cfr. Ferrater, J.:

THÉMATA. Revista de Filosofía, $\mathrm{N}^{\circ} 50$ julio-diciembre (2014) pp.: 303-312 doi: 10.12795/themata.2014.i50.15 
como dirá Leonardo Polo, el sentido de inmanencia que respeta la receptividad y realismo cognoscitivo, supone entender correctamente el descubrimiento aristotélico de la operación inmanente, en donde inmanencia operativa y trascendencia objetiva se exigen y acomodan. Pero eso no es la posición de un acto intencional, que tienda a... su objeto, sino, rescatando lo mejor de la teoría aristotélica, la comprensión de la praxis perfecta ${ }^{13}$ recuperando el verdadero sentido de intencionalidad cognoscitiva ${ }^{14}$.

Cuando en general se habla de intencionalidad en la inteligencia ${ }^{15}$ se quiere superar la dualidad inmanencia-trascendencia que la filosofía moderna había presentado como una dualidad irreductible. Pero en su origen medieval, esa noción planteaba la unificación (inmanencia) de objeto y sujeto en un acto, junto con una trascendencia intencional (el objeto no es el sujeto ni nada de éste). En palabras de Millán-Puelles: «¿Cómo puede darse la unidad de esta doble presencia en un solo acto subjetivo y, respectivamente, cómo es posible que el objeto y el sujeto se unifiquen en ese mismo acto? Esta doble exigencia de diversidad y de unidad debe ser mantenida porque responde a los hechos» ${ }^{16}$.

Diccionario de Filosofía. Madrid: Alianza, 1979) pese a su connotación de «no subjetivo» por mantener una intrínseca referencia o dependencia de un sujeto: «objeto» reclama una referencia a un acto cognoscitivo, con la connotación de presentarse a o ante, ligado a un acto intencional, definido por una mutua referencia; por eso hace preceder a la intención la actualidad: si hay algo que se presenta a o ante es porque previamente es. "Inteligir es un mero actualizar la cosa»; Zubiri, X.: Sobre la esencia. Madrid: Sociedad de Estudios y Publicaciones, 1962; Madrid: Alianza, ${ }^{4} 1972$, p. 113. Lo que se actualiza en la intelección como realidad no tiene pues, carácter preciso de objeto, aun estando inteligido como objeto; lo es por su carácter real (Sobre la esencia cit., p. 382). «La res qua objecta se funda en la previa presentación de la cosa real en cuanto real. Esta realidad de la cosa es la que primariamente pertenece de un modo intrínseco a la integridad de la intelección; es, en efecto, su fundamento inmediato y su término formal directo» (Sobre la esencia cit., p. 405; Inteligencia sentiente. Inteligencia y realidad. Madrid: Alianza Editorial / Madrid: Sociedad de Estudios y Publicaciones, 1980, ${ }^{2} 1981$, p. 193.

[13] Se trata de la noción de energeia o praxis perfecta en Aristóteles. L. Polo dedica una gran atención a la operación inmanente como núcleo de su Curso cit., vol. I, pp. 53-65. En virtud de ella Polo critica a la filosofía de Kant de fisicalismo, por haber confundido la operación inmanente o praxis perfecta del conocimiento con una operación transitiva, una acción física o constructiva (pp. 70 y ss.). La referencia al modo de la posesión del fin (del objeto) es lo que clarifica las dos formas dichas, un poseer en simul y un poseer terminativo o procesual. L. Polo incluye también (como Millán-Puelles) a Husserl en esta crítica, por hacer del polo subjetivo constituyente, si no del contenido del objeto, sí de su carácter de objeto. Curso cit., vol. I, p. 106.

[14] El tender hacia expresaría, propiamente, la intencionalidad volitiva. La flexión del tendere-in donde el in es direccional, para pasar al in de situación la realiza en su análisis de la intencionalidad, Polo, L.: Curso cit., vol. I, pp. 157 y ss.

[15] Polo, L.: Curso cit., vol. I, p. 157 y ss. recuerda en este punto que el in-tendere no sólo es tender a sino especialmente estar en; cfr. pp. 158-160. Además, Polo, L.: Curso cit., vol. II, pp. 55-59, con las consecuencias antropológicas de ese en, pp. 67-72.

[16] Millán-Puelles, A.: Estructura cit., pp. 184-185. Y continúa «Si la autoconciencia subjetiva y la trascendencia intencional se dan, [...] en la unidad de un solo acto indivisible, es indispensable que este acto sea el acontecimiento en el que sujeto y el objeto se unifican, en calidad precisamente

THÉMATA. Revista de Filosofía, №50 julio-diciembre (2014) pp.: 303-312 doi: 10.12795/themata.2014.i50.15 
Pero entonces no hablamos de la intencionalidad fenomenológica, sino del sentido primario y original de intencionalidad en su inflexión inicial en la filosofía medieval ${ }^{17}$. Luego Brentano no recuperó de modo total la riqueza de este concepto; de ahí que podría ser más fructífero atender a él, para utilizarlo en la conceptuación de la inmanencia-trascendencia intelectiva, que es lo que elabora Polo, incorporando así los logros de buena parte de la tradicción filosófica anterior.

Para diferenciar la noción de intencionalidad fenomenológica y medieval debemos recordar que: "la intencionalidad no es un efecto del sujeto ni una constitución aportada por el sujeto, [...] la intencionalidad no es el acto. Husserl pasa de la intencionalidad del objeto a la intencionalidad objetiva, que es una intencionalidad en el sujeto. Consiste en ser un modo referencial del sujeto a la cosa para que ésta devenga objeto constituido en la conciencia» ${ }^{18}$. Si la intencionalidad lo es del acto, no conseguimos superar la ya mencionada escisión del objeto conocido y lo real.

Por lo dicho anteriormente se puede concluir que, si en vez de intencionalidad objetiva (referencia del acto a un objeto) se habla de intencionalidad del objeto -lo intencional es el objeto-, entonces el acto no es referencia al objeto, sino posesión inmanente del objeto; así se da un giro nuevo a la noción de intencionalidad ${ }^{19}$. Admitir que lo intencional es el objeto, y no el acto, es definir

de distintos y sin componer una tercera entidad [...]. Además, es sólo un acontecimiento subjetivo, algo que como hecho real no afecta al ser (intrínseco) del objeto sino, exclusivamente al ser de la subjetividad que se lo hace presente».

[17] Un autor que ha tratado el tema de la intencionalidad en Brentano y la fenomenología en general y retrocedió a su sentido medieval fue Cruz Hernández, M.: La doctrina de la intencionalidad cit. De su «retroceso» a la filosofía escolástica quedaron, como hitos, la intencionalidad en el pensamiento de Avicena y Suárez. No obstante, aunque la intencionalidad fenomenológica es más similar a la corriente esencialista de estos autores, es imprescindible notar que intencionalidad tiene otra acepción en la tradición aristotélico-tomista: la intencionalidad objetiva. Un reciente trabajo sobre la intencionalidad medieval y contemporánea es el publicado en dos monográficos de la revista: Quaestio. Annuario di storia della metafisica, 2010 (10): Prospettive tardo-medievali sull'intenzionalità (F. Amerini, F. Marrone, P. Porro, coord.) y 2012 (12): Intenzionalità e realtà (C. Esposito, P. Porro).

[18] Sellés, J. F.: Conocer y amar. Estudio de los objetos y operaciones del entendimiento y la voluntad según Tomás de Aquino. Pamplona: Eunsa, 1995, p. 17. Cfr. Rábade, S.: La estructura del conocer humano. Madrid: Toro, ${ }^{3} 1985$. Cfr. Polo, L.: Curso cit., vol. I, pp. 114 y ss.; también "Lo intelectual y lo inteligible" en Anuario Filosófico 15-2, 1982, donde sostiene que, perdida o malinterpretada, la unidad de inteligido e inteligible, se crea el problema del dualismo y del puente (el acto es versión al objeto, no lograda, y se establece un problema de relacionar ambos elementos), se deriva también una cosificación de ambos polos, y el problema espacial de cosa externa o cosa en la mente, p. 109.

[19] Polo, L.: Curso cit., vol. I, p. 145; pp. 157 y ss.; al que se opone el in con sentido de situación, «estar-en»; ver también pp. 162-163, donde recuerda en este punto que el in-tendere también tiene el sentido recogido por la etimología latina de inteligencia e intelección: intus-legere, legere-intus: afirmando que «la intencionalidad es penetrante, pero no extra se inspiciendo [...], sino intra se

THÉMATA. Revista de Filosofía, $\mathrm{N}^{\circ} 50$ julio-diciembre (2014) pp.: 303-312

doi: 10.12795/themata.2014.i50.15 
a éste no por su versión $a^{20}$, sino por su actualizar el objeto. En defensa del realismo, es acentuar el estar, el poseer, frente a la referencia o versión como lo previo y fundante de aquélla. Sólo que en ese actualizar el objeto, no se cierra el cognoscente en sí mismo, dada la peculiar naturaleza del objeto cognoscitivo (su ser intencional, y por tanto, trascendente). Mediante la «intencionalidad», se hacía inteligible cómo es posible para la intelección tener lo otro sin hacerlo ella, en una asimilación que queda fuera del ámbito de lo físico (una asimilación intencional ${ }^{21}$ ). La intentio aludía al peculiar carácter ontológico de lo inteligido, de lo tenido en la intelección, que justificaba las pretensiones de inmanencia y alteridad constitutivas del conocer. Se resuelve considerando que el entendimiento «está medido por la realidad» pero no es su copia ${ }^{22}$.

La noción de intencionalidad del objeto nos abre la noción de objeto como «una semejanza que no es una comparación, un parecerse puro, no un parecerse $a »$, no hay copia (que establece una comparación entre la copia y lo copiado) o re-presentación (la misma comparación entre lo presentado y su re-presentación): «En la posesión intencional [...], la intencionalidad pura o cognoscitiva envía a la cosa, pero la intencionalidad no es una copia de la cosa [...] sino que en el enviar, la cosa es conocida. La cognoscibilidad en acto es, a priori, el objeto intencional» ${ }^{23}$. La intencionalidad es al modo de la luz:

considerando", pp. 162-163. Por este motivo, en el caso de Husserl, se trata de un nuevo idealismo: «En la línea seguida por Husserl aparece un idealismo de nuevo cuño: el idealismo de la intencionalidad, el idealismo del ente en cuanto verdadero», p. 250.

[20] Chirinos, M. P.: Intencionalidad y verdad cit., pp. 237-238. Cfr. Sellés, J. F.: Conocer y amar cit., p. 18: «El acto objetiva o intencionaliza pero no es intencional respecto de sí. No se nota la índole del acto en el objetivar del acto». Si queremos hablar del carácter intencional del acto, en realidad no nos referimos al acto mismo sino a la potencia anterior al acto; en este caso, es la visión la que refiere al color, pero el ver es tenerlo ya. Zubiri, X.: Inteligencia y realidad cit., p. 22. Para Polo, el valor originario de lo intencional, que no reside en un tendere-in, un tender a, un dirigirse a, sino en un estar en, entrar-dentro: Polo, L.: Curso cit., vol. I, pp. 158-164.

[21] Así se expresaba este acto intencional: asimilación intencional de la forma ajena en cuanto ajena a diferencia del acto físico más próximo, la asimilación nutritiva. En virtud de ella, no sólo no se hace propio lo asimilado, sino que el acto se hace cognoscitivamente aquello asimilado, midiéndose por él. Esta noción de "ser medido por lo conocido» nos abre la comprensión de la verdad intelectiva que Tomás de Aquino desarrolla en De veritate, 1, y que es el núcleo del realismo medieval. Intencional es, por tanto, la peculiar forma de estar, la forma de lo real en cuanto conocida (esse intentionale frente a esse reale) o, si se quiere, el modo en que la intelección tiene en acto la forma conocida. Intencional menta ese ser de lo conocido en la intelección que le lleva inmediatamente a lo real conocido. En términos de Polo, la asimilación que es posesión del telos, funda la semejanza intencional; Polo, L.: Curso cit., vol. I, p. 138; porque es envío a la cosa, p. 139; de ahí que en la mente no hay algo, realidad, sino intencionalidad; p. 141.

[22] Polo, L.: Curso cit., vol. I, p. 147; 150 ss..

[23] Polo, L.: Curso cit., vol. I, pp. 114 y ss., p. 139. Sobre esta noción de objeto, L. Polo dirá en el lugar citado: «el objeto es la intencionalidad pura o, mejor, la pura intencionalidad o sólo intencionalidad». La clarificación de qué sea intencionalidad objetiva la lleva a cabo considerando los ejemplos de la presencia virtual de la imagen en el espejo (en cuanto la imagen no consiste en

THÉMATA. Revista de Filosofía, Nº50 julio-diciembre (2014) pp.: 303-312 doi: 10.12795/themata.2014.i50.15 
no es algo, "sino el esclarecimiento del ser» ${ }^{24}$, no añade otra realidad, es la intencionalidad.

Olvidar este carácter, plantear el problema moderno del «puente» ${ }^{25}$ (rechazo históricamente realizado tanto por los nominalistas como por los idealistas), introduciendo un objeto "cosificado" y planteando la intencionalidad como comparación con la realidad ${ }^{26}$. Si la intencionalidad es direccionalidad, donde el «in» es un "hacia» referencial, el polo subjetivo se convierte en un polo constituyente (constituyente, no ya del contenido del objeto, pero sí de su carácter de objeto), bien a nivel noético (Husserl), bien a nivel práctico-existencial (Heidegger) ${ }^{27}$. En cambio, si conocer se entiende como la posesión en acto de la forma de lo real (la forma de lo conocido) pero no en su ser real sino intencional, la inmanencia cognoscitiva, según esta interpretación, exige -en la medida en que la forma poseída intencionalmente es de lo real- la trascendencia de la realidad conocida. La forma intencionalmente poseída no "descansa en sí misma" sino que, como tal, remite y nos lleva inmediatamente a aquello de que es forma. De este modo el conocer es un acto que no forma, crea o construye lo conocido, sino sólo su ser conocido (le da el ser intencional a una forma de lo real), siendo determinado por esa forma ${ }^{28}$. Lo que se afirma es la intencionalidad del objeto, no la del acto ${ }^{29}$; en ella insiste Leonardo Polo en su Curso de teoría del conocimiento con la expresión "actualización» para calificar el acto intelectivo: hay una pura actualidad, que es lo que caracteriza al conocimiento, de modo que «no hay objeto e intencionalidad del objeto, sino que el objeto es la intencionalidad misma $»^{30}$.

ella misma, sino en presentar), de la imagen fotográfica (la imagen es el enviarme a la realidad fotografiada, el parecerse) y el retrato (como un mostrar), aun advirtiendo la inadecuación de tales ejemplos.

[24] Polo, L.: Curso cit., vol. I, pp. 152-153.

[25] Cfr. Polo, L.: Curso cit., vol. I, pp. 114 y ss.; también lo aborda en "Lo intelectual y lo inteligible”, Anuario Filosófico, 15, 2, 1982, pp. 103-132.

[26] Polo, L.: Curso cit., vol. I, pp. 145-146.

[27] La separación de la intencionalidad de todo elemento psíquico y real la aborda L. Polo en Nominalismo, idealismo y realismo, Pamplona: Eunsa, 1997, pp. 16-18, además de en Curso cit., vol. I, pp. 120 y 149. Por otro lado, Polo trata con extensión la diferente intencionalidad del conocer y querer en ambos lugares. Incluso afirma que la intencionalidad del acto supone una confusión de lo propiamente intelectivo como la intencionalidad volitiva. No entro aquí a considerar este tema.

[28] Llano, A.: El enigma cit., p. 25, 49, 120, 124, 144, 271... Pero debe mantenerse al nivel del acto (acto perfecto, con terminología aristotélica) no reduciéndola a trasunto de formas, o a acciones transeuntes o poiéticas.

[29] Aquí se encontraría una diferencia esencial entre la noción de intencionalidad clásica y la que desde Franz Brentano es utilizada por la fenomenología del siglo XX; un tema que ha sido tratado en muchos lugares (como en Chirinos, M. P.: Intencionalidad y verdad cit.; Cruz Hernández, M.: La doctrina de la intencionalidad cit.; y desde las tesis de Tomás de Aquino en Hayen, A.: L'intentionnel cit.; Moya, P.: La intencionalidad cit.).

[30] Polo, L.: Curso cit., vol. I, p. 163; un poco antes había indicado que «el conocimiento en acto es

THÉMATA. Revista de Filosofía, $\mathrm{N}^{\circ} 50$ julio-diciembre (2014) pp.: 303-312

doi: 10.12795/themata.2014.i50.15 
Polo da cuenta de este carácter de actualización en la profundización sobre la tesis aristotélica de la operación inmanente (enérgeia), mediante la que se explicaba tanto la inmanencia operativa como la trascendencia objetiva ${ }^{31}$, desde el análisis del conocer como operación - una noción central de su teoría del conocimiento: conocer es enérgeia o praxis perfecta, operación inmanente ${ }^{32}$.

co-actual con lo conocido en acto. Y la actualidad poseída por la operación cognoscitiva en pretérito perfecto es el objeto mismo en tanto que intencional».

[31] Un interesante estudio que Leonardo Polo prologa dedicado a la noción de enérgeia o praxis en Aristóteles, es el de Yepes, R.: La doctrina del acto en Aristóteles. Pamplona: Eunsa, 1993.

[32] Así, Polo, L.: "Lo intelectual y lo inteligible" cit., pp. 122-132; Curso cit., vol. I, p. 5: «puesto que el conocimiento humano no es solamente operativo sino también habitual»; donde el hábito es consecutivo a la operación, pero no es menor que ella sino potencializador y algo más que una operación, abre la intelección más allá de la operación. Este desarrollo le ocupa los cuatro volúmenes de su Curso de teoría del conocimiento y los dos de su Antropología trascendental.

THÉMATA. Revista de Filosofía, Nº50 julio-diciembre (2014) pp.: 303-312 doi: 10.12795/themata.2014.i50.15 